\title{
Study on Technological Innovation Mechanism in Private Enterprises
}

\author{
$\mathrm{Li} \mathrm{Ma}{ }^{\mathrm{a},{ }^{*}}$, Shuang $\mathrm{Li}^{\mathrm{b}}$ \\ Tianjin University of Science \& Technology, Tianjin, 300222 China. \\ *,amai0720@163.com, b1508073923@qq.com
}

Keywords: Private enterprise, Science and technology innovation, Mechanism.

\begin{abstract}
The private enterprises are facing a big challenge since China entered the WTO (world trade organization). Therefore, how to face this challenge and keep continuing development have become the urgent issues that the private enterprises need to settle. In order to improve their competition ability and keep developing, three different science and technology innovation mechanisms for private enterprises were put forward in this paper, including the self-innovation mechanism from the inside, the imitation innovation mechanism from the enterprise cluster, the cooperative and innovation mechanism from the industry-university-research (IUR) field.
\end{abstract}

\section{Introduction}

The private enterprises in our country have achieved a rapid development in recent years. However, there are many problems exist [1]. The small enterprises are mainly relaying on the imitation innovation because they lack of the manpower and financial resources to do self-independent innovations [2]. The large enterprises can rely on the independent innovation and they pay more attention to the cooperative innovation of the industry-university-research (IUR) model. The research and development (R\&D) input of the independent innovation enterprises can reach more than $5 \%$ of the total sales income as reported [3]. The first problem the self-independent innovation faced is lacking of the creative talents, and then is the big risk of innovation process. The most profit method is the independent innovation and the best way to improve the innovation ability is the cooperative innovation of the IUR model as most of the enterprises reveal.

\section{The Present Situation of Technological Innovation in Private Enterprises}

The characteristics of the domain private enterprises at present are as follows. First, there are a large number of enterprises but most of the enterprise scales are small, therefore the operating models are flexible. Secondly, most of the private enterprises are willing to do independent innovations but commonly they lack of R\&D funds, the innovation ability and the risk-resistance ability. Lastly, except some enterprises with strong economic and technology strengths, most private enterprises do not have the innovation ability. Besides, in order to overcome the resource constraints and improve the overall innovation capacity, there are kinds of cooperative innovation models exist automatically among the enterprises and the universities, which have showed significant benefit for the enterprises' technology development. Based on the present situation as stated above, the right choice for the enterprises is imitation innovation, starting with ideas and institutional innovations and then realize the technological innovation.

\section{The Three Technological Innovation Mechanisms of The Private Enterprises}

There are three main technological innovation mechanisms can be concluded from the private enterprises, the self-independent innovation mechanism from the inside, the imitation innovation mechanism from the enterprise group and the cooperative innovation mechanism from the IUR. Among them, the first mechanism is the core part of the general model of the technological innovation mechanisms, the last two mechanisms are selectively and dynamically and serving for the 
first mechanism [4]. The general model of the private enterprise innovation mechanism is shown in Fig. 1.

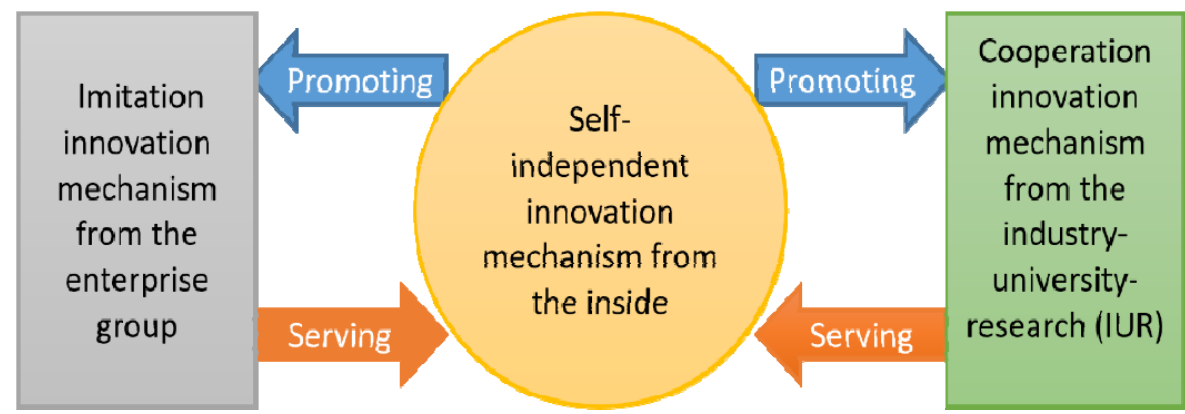

Fig.1 The general model of the private enterprise technological innovation mechanism

\subsection{The Self-Independent Innovation Mechanism from the Inside.}

The key method for the enterprises to remain invincible is to improve the whole core competitiveness. The self-independent innovation means that, one enterprise should depend on self-effort to break through the production technologies, overcome the technical difficulties, and to complete the commercial process of the technologies and gain the commercial profit based on the innovation promotion $[5,6]$. Like the engine on a motorbike, sufficient research fund input can gain high innovation output. The success probability of the self-independent innovation will be improved under this investment model. The self-independent innovation needs high cohesive force-bonded creative team, sufficient research fund investment, and the market-insight and sensitively policy maker to lead the development of the high technology industry [7].

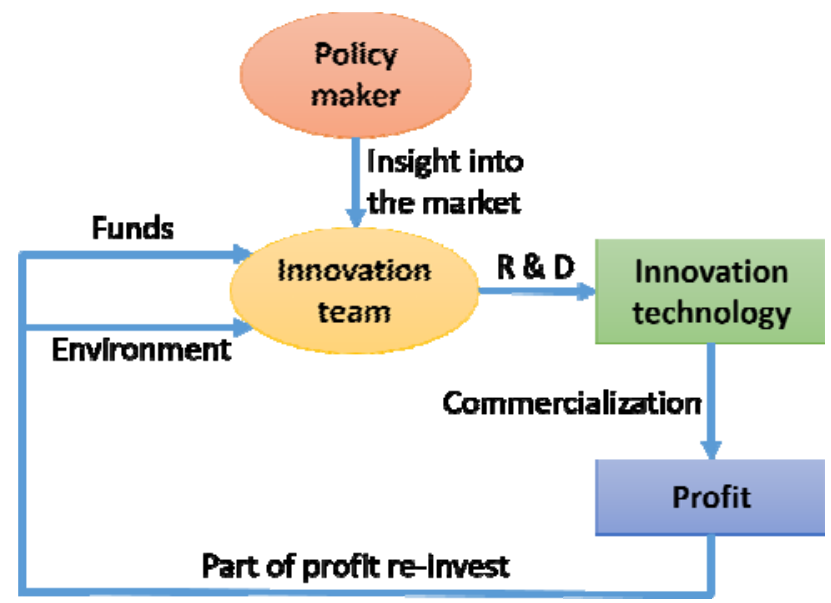

Fig.2 The self-independent innovation mechanism from the enterprise inside

As shown in Fig.2, the self-independent innovation mechanism from the enterprise inside is a recycle process of the fund investment and the commercial profit. When the enterprise gains the monopoly profit from the innovation technologies, more capital will be invested into the next technology innovation process and this makes the profit more and more. The self-independent innovation mechanism is the first choice of some powerful private enterprises because it has some outstanding advantages. The self-independent innovation can make the enterprise to be the leader in a special field. It also may initiate some other innovations in the related technology fields to help the enterprise expanding the development space and improving the popularity. Moreover, the self-independent innovated technology can form a technical barrier and help the enterprise gaining unprecedented monopoly profit, and indeed can realize the virtuous cycle between the high financial investment and the high commercial profit.

However, it must be pointed out that the self-independent innovation mechanism is risky and long-term return cycle, although it has some outstanding advantages when compared to the other innovation mechanisms. Therefore, generally only the powerful and large enterprises are willing to try this self-independent innovation method. 


\subsection{The imitation Innovation Mechanism from the Enterprise Group.}

Among the private enterprises, the large enterprises only take a small part and the remaining are small and medium-sized enterprises with flexible and diverse forms. These small and medium-sized enterprises do not qualify the self-independent innovation conditions because of lacking enough economic strength and technological innovation ability. They must take full advantage of the outside resources to make up for its own shortcomings and defects and thus can survive in the competitions. The enterprise group is the linkage of the enterprises in the same region or commercial cooperative, and also is the competitive power resource of one country or district, which can speed up the innovation and spreading processes of new knowledge and technologies. The enterprise group gathers many similar and highly related enterprises, and the impossible innovations by the single enterprise can be completed with the enterprise group in a collective form, which can benefit several enterprises simultaneously.

The innovation mechanism from the enterprise group is called the imitation innovation mechanism, which is defined as that the innovation ideas and behaviors of the enterprise are learning from the forefathers, and then develop out the competitive productions in terms of performance, quality, and price by learning the success and failure lessons, purchasing or decoding the core classified technologies, and improving or perfecting the old technologies [8]. This behavior can help the small and medium-sized enterprises strength their competition positions and gain good commercial benefits. Imitation innovation is a process including learning, absorption and imitation innovation. Many outstanding enterprises make innovation gradually by learning and trying especially the small and medium-sized enterprises, because they are qualified with well learning abilities and they can accumulate wealth and experience for the indeed innovation process by combining the ability improvement and the innovation success together.

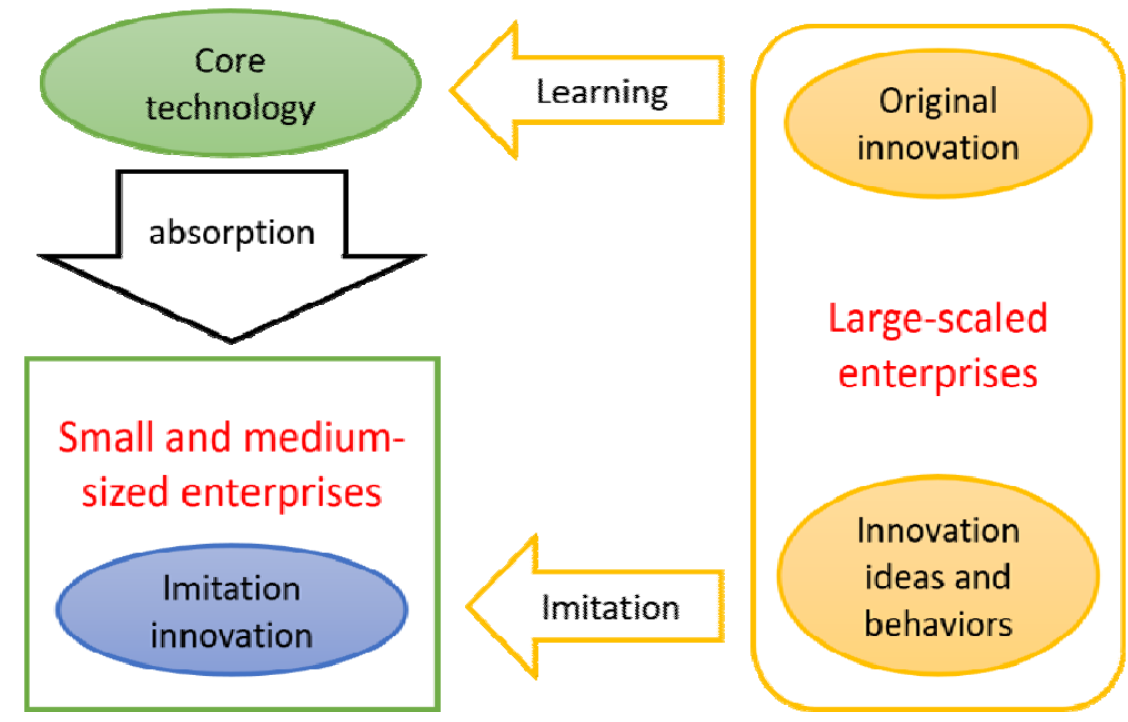

Fig.3 The diagram of imitation innovation mechanism from the enterprise group

The imitation innovation process is vividly shown in Fig.3, including the process of enterprise integration into enterprise cluster, the absorbing of innovation achievements and the re-innovation process based on the self-requirement. The enterprise will not survive in the competitive environment just by imitation alone, and the small and medium-sized enterprises should make innovation development based on the imitation process.

\subsection{The Cooperative Innovation Mechanism from the IUR.}

The cooperative innovation mechanism from industry-university-research (IUR) is defined as the behavior of complete the innovation process by taking full advantages of the industries, the universities and the research institutes through labor division and cooperative together [9]. The enterprises can lead the research directions and realize the continuous innovation because they are closed to the market and have a good knowledge of the customer's present and future technology demands. The university and the research institute have some advantages in knowledge and 
technology aspects, but they lack of the ability to grasp the customer market and translate the technology into commercial production, which is really what the enterprises skilled. Therefore, the industry and the university-research often play as different characters in the technical innovation process.

Except the technical supporting from the government, the university and the research institution can provide effective supporting for the enterprises to develop technical innovations when the enterprises facing with resource and environment difficulties in innovation process. The universities and the research institutes are not only equipped with outstanding talents, plentiful knowledge and good innovation environment, but also equipped with the most advanced experimental equipment and specialized research and development labs. Three different cooperative methods can be formed among the enterprise, university and research institute. The first one is the simple technical purchase, which means that the cooperative relationship will come to an end after the enterprise finishes purchasing the needed technology from the university or the research institute. The second method is only make cooperative on one special technology. This process can be described as follows, the university or the research institute obtain the technical demands from the enterprise and then send someone to do investigations in the enterprise to make clear the operate situation, after that they work together to complete the technical innovation project and allocate the profit by associated proportion. The last cooperative method is to construct the permanent partner relationship, and this form breaks the traditional restrains of technical and service consultant level, which means the permanent cooperative relationship is built among them. In fact, some researchers from the university or the research institute play a role as the bridge of the cooperative relationship when working in the private enterprise. This method can help them realize the resource exchanges and the complementary advantages. The cooperative innovation mechanism from the IUR is drawn out as shown in Fig. 4.

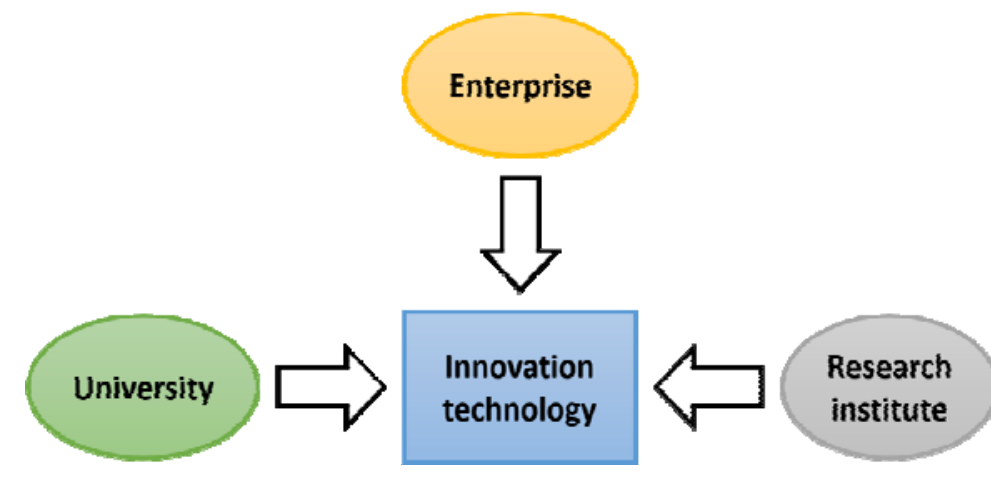

Fig.4 The diagram of the cooperative innovation mechanism from the IUR

It is worth noting that the cooperative among the enterprise, university and research institute is a bi-directional income process. The university and research institute can help the private enterprise overcome the problems of technology innovation process, on the other hand this can benefit the researchers in finding new research items and make the theoretical knowledge combine with the producing process. Therefore, the cooperative among the IUR is benefit for not only the powerful large enterprises but also for the small and medium-sized enterprises.

\section{Summary}

In order to improve the whole development of the private enterprises and boost the technical innovation ability. The large-scaled private enterprises should use the self-independent innovation mechanism effectively and build up their own innovation platform to enlarge the operation scale and lead the industrial development by introducing more manpower, material and financial resources into the technical innovation process. Meanwhile, the enterprises should cultivate the cooperative innovation mechanism from IUR to improve the innovation ability by taking full advantage of the manpower and the experimental conditions served by the universities and research institutes. The small and medium-sized enterprises can use the imitation innovation mechanism to improve their own innovation abilities by imitating the innovation ideas, the innovation models and the innovation 
products of the large-scaled enterprises, and then they can work with the related enterprise group or the university and the research institute to make cooperative innovations. In brief, the private enterprises should choose the suitable innovation mechanism based on their own conditions to develop their own technology and build their own brand.

\section{Acknowledgements}

This research was financially supported by the Key Project of Scientific and Technological Development Strategic Plan of Tianjin Municipal Science and Technology Commission (No.: 16ZLZDZF00160).

\section{References}

[1]. Paley, T.I., the Revival, Legitimization, and Development of Private Enterprise in China. Palgrave Macmillan US, 2015.

[2]. Duane, H. and A.R.B. Chic, Institutional Environment, Political Connection and Financial Constraints---Evidence from Private Enterprise in China, Business \& Management Research, vol. 1(1), pp. 133-140, 2012.

[3]. Zhang, Y. and H. You, The Impact of the FDI Enterprise on Science and Technology Innovation Ability of the Private Enterprises in China, Journal of Industrial Technological Economics, vol. 9, pp. 96-104, 2014.

[4]. Qin, Z., Models of trust-sharing in Chinese private enterprises, Economic Modelling, vol. 28(3), pp. 1017-1029, 2011.

[5]. Yang, D.Y., D. Li, and Y. Bay, Simulation Model Construction and Analysis on Effects of Intellectual Property Protection for Enterprise Independent Innovation, International Journal of Advancements in Computing Technology, vol. 5(7), pp. 123-127, 2013.

[6]. Jun, X.U., T.F. Ran, B. School, and J.N. University, Research on the Integrated Driving Mechanism of Private Enterprises' Independent Innovation under the Perspective of the Supply-Side Reform, Soft Science, vol. 31(9), pp. 101-105, 2017.

[7]. Pang, J. and C. Liu, Game analysis of self-innovation and imitating innovation, Scientific Management Research, vol. 21(6), pp. 18-22, 2003.

[8]. Jiao, M. and W.G. Dou, The Role of Imitation Innovation in the growth of Chinese enterprises: A Case Study of Ten cent, Journal of Huainan Institute of Technology, vol. 12(7), pp. 86-88, 2014.

[9]. Sun, D., Research on Cooperative Innovation of Small and Medium-sized Private Enterprise, Scientific Management Research, vol. 28(3), pp. 12-15, 2008. 